\title{
BEN As a Presumptive Target Recognition Molecule during the Development of the Olivocerebellar System
}

\author{
Alain Chédotal, ${ }^{1}$ Olivier Pourquié, ${ }^{2}$ Frédéric Ezan, ${ }^{1}$ Hélène San Clemente, ${ }^{2}$ and Constantino Sotelo \\ 1 Institut National de la Santé et de la Recherche Médicale, Neuromorphologie, Développement, Evolution, Hôpital de la \\ Salpêtrière, 75651 Paris Cedex 13, France, and 2Institut d'Embryologie Cellulaire et Moléculaire du Centre National de la \\ Recherche Scientifique et du Collège de France, 94736 Nogent-sur-Marne Cedex, France
}

\begin{abstract}
It has been shown previously that in the chick embryo the cell adhesion molecule BEN/SC1/DM-GRASP is expressed by neurons in the inferior olive (IO) and by their terminal axonal arbors in the cerebellar cortex, the climbing fibers (Pourquié et al., 1992b). Here, new information on the expression of BEN during the formation of the olivocerebellar projection adds the important notion that BEN is also expressed by the cerebellar targets of inferior olivary axons, Purkinje cells (PCs) and deep nuclear neurons. This expression is transient, starting at E7-E8 and vanishing shortly after hatching. More importantly, BEN expression is restricted to precise subsets of 10 neurons and PCs. In the cerebellar cortex, BEN-immunoreactive (BEN-IR) structures are not found randomly but are distributed according to a reproducible pattern of parasagittal stripes. A maximum of
\end{abstract}

four distinct sagittal stripes is found in each lobule, along the whole rostrocaudal extent of the cerebellum. Moreover, BENexpressing stripes belong to two classes; one contains BEN-IR climbing fibers terminating on BEN-IR PCs and the other, more frequent class is solely composed of BEN-IR climbing fibers. Organotypic cultures of isolated cerebella have shown that the expression of BEN in the $\mathrm{IO}$ and in the cerebellum arise independently, probably because of an intrinsic developmental program. Thus, the cell adhesion molecule BEN meets all criteria for a recognition molecule involved in the formation of the olivocerebellar projection.

Key words: inferior olive; Purkinje cell; climbing fiber; chick; cell adhesion; projection map formation
A major goal in developmental neurobiology is to determine the cellular and molecular mechanisms that give rise to the orderly pattern of neuronal connectivity. Most of our current understanding of these mechanisms has been obtained from studies on the retinotectal system (Baier and Bonhoeffer, 1992; Holt and Harris, 1993), in which adjacent retinal ganglion cells project toward adjacent tectal neurons. Another system that could complement the study of the formation of projection maps is the olivocerebellar system. This projection is arranged into distinct cortical compartments, forming adjacent parasagittal bands (the longitudinal organization of the cerebellum). Clusters of olivary neurons project into the sagittal bands, but nearby clusters do not project to adjacent bands. Thus, the projection is discontinuous, with sharp boundaries, and ordered with respect to the local origin of the olivary neurons (Azizi and Woodward, 1987; BuisseretDelmas and Angaut, 1993).

Studies on the development of the olivocerebellar system in rodents have revealed that, before the entry of olivary fibers into the cerebellar parenchyma, there is a simultaneous but independent parcellation of the cerebellar cortex and the inferior olive (IO). This compartmentation results from the transient expres-

\footnotetext{
Received Jan. 19, 1996; revised Feb. 23, 1996; accepted Feb. 29, 1996

We thank Prof. N. Le Douarin and Drs. P. Gaspar and F. Rossi for their critical reading of this manuscript, Dr. E. Pollerberg for the gift of the $4 \mathrm{H} 5$ antibody, and Drs. D. E. M. Lawson and W. Hunziker for the gift of the anti-calbindin antibodies. We also thank Denis Lecren for his photographic work and C. Bréant and Dr. Meritxell Lopez-Gallardo for their contribution.

Correspondence should be addressed to Dr. Constantino Sotelo, INSERM U106, Ncuromorphologic, Dévcloppement, Evolution, Bâtiment de Pédiatrie, Hôpital de la Salpêtrière, 47 Boulevard de l'Hôpital, 75651 Paris Cedex 13, France.

Dr. Chédotal's present address: University of California, Department of Molecular and Cell Biology, Room 519, Life Sciences Addition, Berkeley, CA 94720.

Copyright (C) 1996 Society for Neuroscience $0270-6474 / 96 / 163296-15 \$ 05.00 / 0$
}

sion of a unique combination of proteins by clusters of Purkinje cells (PCs) and IO neurons (Wassef and Sotelo, 1984; Wassef et al., 1985, 1992a; Sotelo and Wassef, 1991), implying the involvement of a genetic program (Oberdick et al., 1993).

We have therefore suggested that the major mechanism involved in the formation of the olivocerebellar topography is the existence of matched positional or guidance cues between clusters of PCs and corresponding clusters of IO neurons (Sotelo and Wassef, 1991; Wassef et al., 1992a,b). This concept has its roots in the chemoaffinity hypothesis (Sperry, 1963). One further step toward the validation of our suggestion would be the demonstration that cell surface molecules are expressed both on IO neurons and axons and on their cerebellar targets.

The immunoglobulin-like cell adhesion molecule called BEN (Pourquié et al., 1990, 1992a,b), SCl (Tanaka et al., 1991), or DM-GRASP (Burns et al., 1991) has been shown recently to be expressed on IO neurons and axons in the chick embryo (Pourquice et al., 1992a,b). Furthermore, in the chick cerebellar system, $\mathrm{BEN}$ is the only known adhesion molecule restricted to the IO and expressed on climbing fibers (the terminal fields of IO axons) during their axonogenesis and synaptogenesis (Pourquié et al., 1992b). Thus, we decided to reexamine the spatio-temporal pattcrn of BEN cxpression in the dcvcloping chick olivocerebellar system. Through the analysis of BEN mRNA and protein expression, we found that BEN is transiently expressed in a subpopulation of IO neurons, in a subset of PCs with a zonally restricted pattern, and in a subset of deep nuclear neurons. The formation of these compartments appears to be an intrinsic process, independent of any interaction between climbing fibers and PCs, suggesting that $\mathrm{BEN}$ is involved in the formation of the olivocerebellar projection. 


\section{MATERIALS AND METHODS}

\section{Immunocytochemistry and in situ hybridization}

Sample preparation. Fertile White Leghorn hens' eggs were incubated at $38^{\circ} \mathrm{C}$ and fixed at various stages (Hamburger and Hamilton, 1951) from embryonic day 6 (E6) to $1 \mathrm{~d}$ after hatching. Embryos were collected, staged, and perfused through the heart with a solution of $4 \%$ paraformaldehyde $(4 \% \mathrm{PF})$ in $0.12 \mathrm{M}$ phosphate buffer, $\mathrm{pH} 7.2-7.4$. The brains were dissected out and left overnight in the same fixative.

For immunocytochemistry and radioactive in situ hybridization on cryostat sections, the brains were postfixed $2 \mathrm{~d}$, cryoprotected, embedded in a solution of $7.5 \%$ gelatin containing $15 \%$ sucrose, and frozen at $-60^{\circ} \mathrm{C}$ in isopentane. Serial sections $(20-40 \mu \mathrm{m})$ were collected on gelatin-coated slides. For nonradioactive in situ hybridization, dissected brains were also postfixed overnight, embedded in a $30 \%$ albumin and $0.5 \%$ gelatin solution, and sectioned $(150-200 \mu \mathrm{m})$ with a vibratome. Slices were subsequently dehydrated in a graded methanol series $(25,50$, $75,100 \%$, diluted in PBS containing $0.1 \%$ Tween 20 ) and stored at $-20^{\circ} \mathrm{C}$ until use.

Immunocylochemistry. Sections were rinsed twice in a PBS solution containing $0.25 \%$ Triton X-100 and incubated overnight at room temperature with (1) a mouse monoclonal anti-BEN antibody $(1: 30,000$; see Pourquié et al., 1990) for single immunostaining; (2) a mixture of rabbit polyclonal anti-BEN antibody (1:300, kindly provided by Dr. E. Pollerberg; see Pollerberg and Mack, 1994) and a mouse monoclonal anticalbindin- $\mathrm{D}_{28 \mathrm{~K}}$ antibody (1:5000, provided by Dr. W. Hunziker; see Pinol et al., 1990) for double-immunofluorescence staining; or (3) a mixture of the monoclonal BEN and rabbit polyclonal anti-calbindin antibody (1: 10,000, gift of Dr. D. E. M. Lawson) (see Spencer et al., 1976) for the $\mathrm{DAB}$ and fluorescence double-immunostaining.

For single immunostaining and $\mathrm{DAB} /$ fluorescence double-labeling, scctions were rinsed, incubated for $1 \mathrm{hr}$ in a biotinylated anti-mouse secondary antibody (1:200), and processed with the ABC solution (1:100, both purchased from Vector Laboratorics, Burlingame, CA). Peroxidase was revealed using DAB as a chromogen. For DAB/fluorescence doublestaining experiments, embryos were rinsed after the DAB reaction and then incubated $1 \mathrm{hr}$ in an FITC-conjugated anti-rabbit antibody (1:100, Silenus, Hawthorne, Australia).

For double-fluorescence immunolabeling, sections were incubated for $1 \mathrm{hr}$ with a biotinylated anti-rabbit antibody (1:200, Vector Laboratories) and then in a mixture of FITC-conjugated anti-rabbit antibody (1:100, Silenus) and Texas red-conjugated streptavidin (1:150, Life Technologies, Gaithersburg, MD). Preparations were mounted with Eukitt or Mowiol (Calbiochem, Lucerne, Switzerland) for fluorescence immunostaining. Some sections were only Nissl-stained with cresyl violet/thionine.

Nonradioactive in situ hybridization. A $1.5 \mathrm{~kb}$ SacII-HpaII fragment, derived from the BEN cDNA corresponding to the extracellular portion of the molecule and cloned in a pGEM-3Z vector, was used as a probe. This cDNA covers all Ig-like domains. The linearized plasmid was transcribed from the corresponding promoter with SP6 RNA polymerase to produce an antisense probe and with $\mathrm{T} 7 \mathrm{RNA}$ polymerase to produce a sense probe. The probes were synthesized with T7 or SP6 RNA polymerases in the presence of $0.17 \mathrm{~mm}$ digoxigenin-UTP (Boehringer Mannheim, Mannheim, Germany), $0.5 \mathrm{~mm}$ ATP, $0.5 \mathrm{~mm}$ CTP, $0.5 \mathrm{~mm}$ GTP, and 0.33 mm UTP (Promega, Madison, WI) and were not hydrolyzed after synthesis. Hybridization was done after a protocol described previously (see Bally-Cuif et al., 1993).

Radioactive in situ hybridization. ${ }^{35}$ S-labeled antisense- and sensecRNA probes were prepared using a Promega transcription kit, following the manufacturer's instructions. Cryostat sections were fixed in $4 \% \mathrm{PF}$ for $15 \mathrm{~min}$ at room temperature (RT), rinsed twice in $2 \times$ PBS and once in water, and placed into $0.25 \%$ acetic anhydride in $0.1 \mathrm{M}$ triethanolamine for $10 \mathrm{~min}$ at RT. After acetylation, sections were rinsed in $1 \times$ PBS, dehydrated in $30 \%, 50 \%, 70 \%, 85 \%, 95 \%$, and $100 \%$ ethanol and air dried for $30 \mathrm{~min}$. Sections were hybridized overnight at $58^{\circ} \mathrm{C}$ with $2.10^{6}$ $\mathrm{cpm}$ of ${ }^{35} \mathrm{~S}$-labeled probes in $40 \mu \mathrm{l}$ of hybridization solution $(50 \%$ formamide, $0.3 \mathrm{M} \mathrm{NaCl}, 20 \mathrm{~mm}$ Tris $\mathrm{HCl}, \mathrm{pH} 7.6,5 \mathrm{~mm}$ EDTA, $10 \mathrm{~mm}$ $\mathrm{NaH}_{2} \mathrm{PO}_{4}, 10 \%$ dextran sulfate, $1 \times$ Denhardt's, $10 \mathrm{mg} / \mathrm{ml}$ yeast tRNA). After one rinse in $2 \times \mathrm{SSC}$ (RT, the next SSC washes containing $1 \mathrm{~mm}$ DTT) and two in $2 \times \mathrm{SSC}$ (RT), sections were incubated $30 \mathrm{~min}$ in RNase $\Lambda(20 \mathrm{mg} / \mathrm{ml})$ at $37^{\circ} \mathrm{C}$. Slides were washed with $2 \times \mathrm{SSC}(10 \mathrm{~min}, \mathrm{RT}), 1 \times$ SSC ( $10 \mathrm{~min}, \mathrm{RT}), 0.1 \times \mathrm{SSC}(30 \mathrm{~min}, \mathrm{RT}$, three times), and $0.5 \times \mathrm{SSC}(10$ min, RT, twice) before dehydration in graded alcohols. Slides were dipped in Kodak NTB2 emulsion, exposed from $5 \mathrm{~d}$ to 2 weeks, devel- oped, and mounted. Some sections were counterstained with toluidine blue.

\section{Organotypic culture of embryonic cerebella}

Brains from stage $\mathrm{HH} 30$ to $\mathrm{HH} 35$ chick embryos were quickly removed and placed into ice-cold Gey's balanced salt solution with $5 \mathrm{mg} / \mathrm{ml}$ glucose. The cerebellar primordium was removed with small forceps and placed on the membrane of a $30 \mathrm{~mm}$ Millipore culture insert plate (pore size $0.4 \mu \mathrm{m}$; Millicell-CM, Millipore, Bedford, MA) in $100 \mathrm{~mm}$ culture dishes, at $37^{\circ} \mathrm{C}$ in a humidified atmosphere with $5 \% \mathrm{CO}_{2}$ (Stoppini et al., 1991). The culture medium, changed every 2-3 d, consisted of basal medium (Eagle's, 50\%), HBSS (25\%), $10 \mathrm{~mm}$ glutamine, $5 \mathrm{mg} / \mathrm{ml}$ glucose, and $25 \%$ (first week) or $15 \%$ (following days) horse serum. After various culture periods (between 4 and $40 \mathrm{~d}$ ), cerebellar explants were fixed with $4 \% \mathrm{PF}(1 \mathrm{hr})$ and processed for immunocytochemistry as described above. In some cases, and before immunocytochemistry, fixed cerebellar explants were embedded in a mixture of $7.5 \%$ gelatin containing $15 \%$ sucrose and finally frozen at $-50^{\circ} \mathrm{C}$ in isopentane. Sections $(50 \mu \mathrm{m})$ were cut with a cryostat and placed on gelatin coated slides.

\section{DiI tracing}

Embryos between stages $\mathrm{HH} 29$ (E6) and $\mathrm{HH} 39$ (E13) were fixed with $4 \%$ PF. Crystals of DiI or 1,1-dilinoleyl-3,3,3',3'-tetramethylindocarbocyanine perchlorate (Fast-DiI, Molecular Probes, Eugene, OR) were inserted in the left or right side of the cerebellum (retrograde labeling) or in the medulla oblongata at the level of the IO (anterograde labcling). Fast-DiI has bcen shown to provide more rapid axonal tracing than DiI because of alteration of the alkyl tail (Friedland et al., 1995). Embryos were kept in 4\% PF for 3-6 weeks at $37^{\circ} \mathrm{C}$. The brains were dissected out and cut with a vibratome $(75-100 \mu \mathrm{m})$.

\section{Three-dimensional reconstructions and computerized plots}

For three-dimensional reconstructions, tissue sections were drawn with a camera lucida. The drawings were digitized with a WACOM graphic table, using the CANVAS 3.0.6 software (Deneba) and the 3D TURBORENDER 6.0.6 software to create a three-dimensional orientable model of the tissue and translate it into a synthetic image.

Computcrizcd plots of tissue contours and of BEN and CaBP immunostaining were acquired using the CARTO software (Alcatel-TITN-Answare).

\section{RESULTS}

\section{Development of the olivocerebellar projection}

The time sequence in the development of the olivocerebellar projection was studied by injecting DiI or Fast-DiI into the cerebellum or the IO of E6-E13 fixed embryos.

\section{Retrograde axonal tracing}

From E9, when DiI/fast-DiI were injected into the cerebellum, many of the IO neurons were retrogradely labeled (Fig. 1A,B). The projection was almost exclusively contralateral. The vestibular system and other unidentified dorsal bulbar tracts were also labeled (not shown). No retrograde tracing of the IO was obtained before E9.

\section{Anterograde axonal tracing}

As the injection sites were large and extended far beyond the IO, extracerebellar fibers such as spinocerebellar fibers (Okado et al., 1987) may have been labeled besides the olivocerebellar axons. We therefore searched for DiI-labeled fibers within the PC plate, because of all the extracerebellar fibers, only those emerging from the IO neurons ended exclusively in the PC layer. By E10, numerous labeled axons in the developing granular layer had their terminal tips within the PC layer (Fig. $1 C, D$ ). These fibers were thin, had irregular contours and terminated by small growth cones of a simple type (Fig. 1C,D); these corresponded to the first climbing fibers reaching the PCs.

Taken together, all of the axonal tracing data indicate that in 

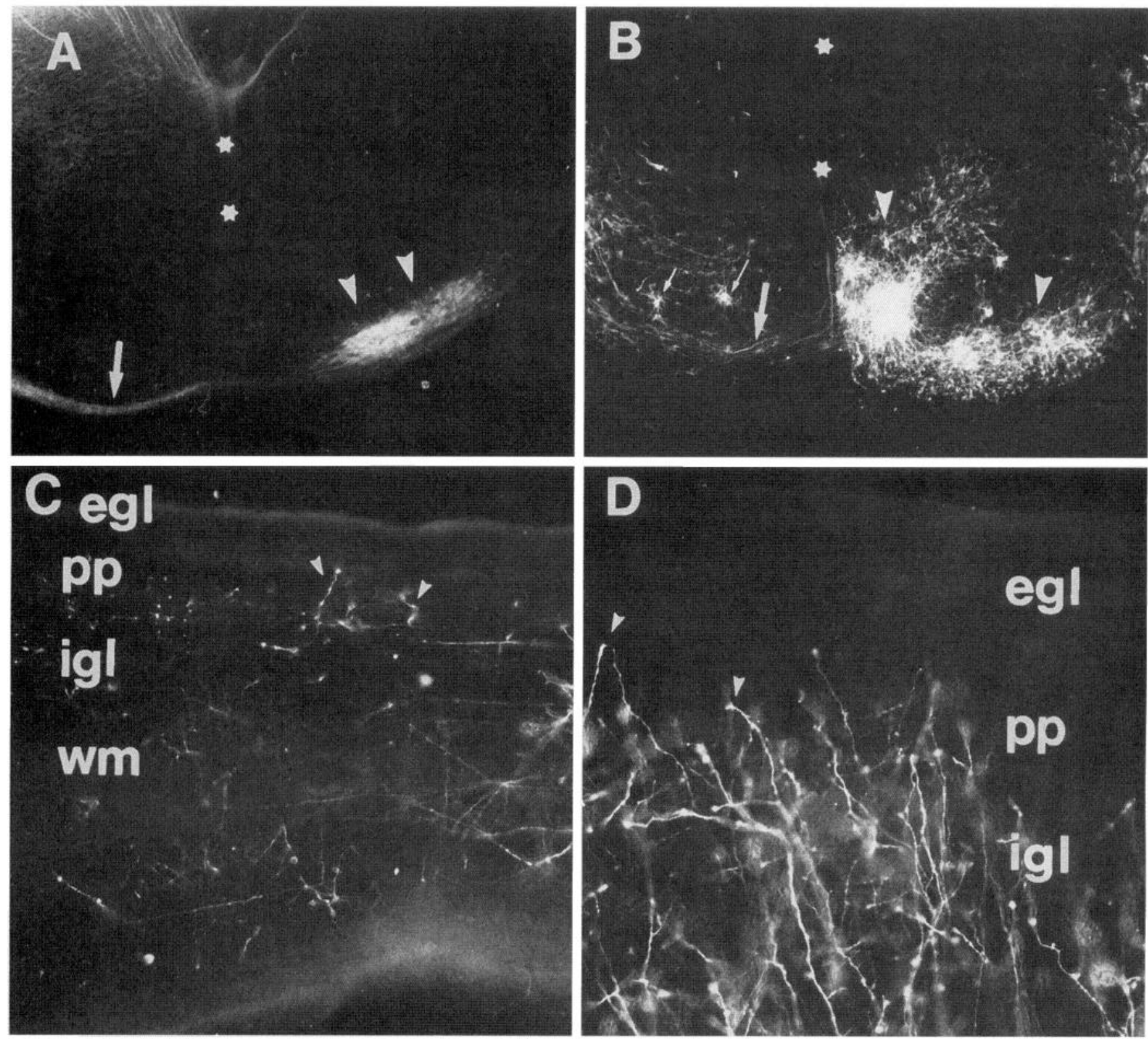

Figure 1. Axonal tracing experiments to determine the time of onset of the formation of the olivocerebellar projection. $A$, IO of an E9 embryo illustrating the retrogradely labeled neurons first observed after Fast-DiI injection in the contralateral cerebellar plate. The thick arrow points to the axonal bundle originated from the labeled neurons (arrowheads), just after their midline crossing (the stars mark the location of the floor plate). B, One day later (E10), most of the contralateral IO neurons are retrogradely labeled (arrowheads), whereas only very few are labeled in the ipsilateral side (thin arrows). The thick arrow and the stars mark, respectively, axons after the midline crossing and the floor plate as in $A$. $C$, E10 cerebellum after DiI application into the contralateral IO. Note DiI-labeled axons within the prospective white matter $(w m)$ and IGL $(i g l)$. These axons reach the PC plate $(p p)$, where they exhibit a beaded appearance (arrowheads), but they do not enter the EGL (egl). D, Same cerebellum as in $C$ but a higher magnification to illustrate afferent axons in the $i g l$ and $p p$. Note that these axons bear numerous growth cones (arrowheads). The latter appear as simple buds, occasionally provided with short filopodia, suggesting that by $\mathrm{E} 10$ axonal growth is still very active. Magnification: $A, 40 \times ; B, 50 \times ; C, 100<; D, 120 \times$.

chick embryos IO axons enter the cerebellum just before E9 but reach PCs at E10 only.

\section{BEN is transiently expressed by a subset of inferior olivary neurons}

We have used the nomenclature for the IO subdivisions in birds of Vogt-Nilsen (1954), who recognized two main lamellae, a large dorsal one and a smaller ventral one, which can be further subdivided into seven parts (see Fig. 4). In birds as in mammals, IO neurons derive from the so called "rhombic lip" in the alar plate of the rhombencephalon (Harkmark, 1954). In the chick, these neurons are generated from the third to the fifth day of incubation (E3-E5; Armstrong and Clarke, 1979) and migrate between E5 and E7 from the dorsal to the ventral aspect of the medulla through a process of superficial cell migration (Harkmark 1954, 1956; Tan and Le Douarin, 1991). The dorsal lamella of the IO appears first at E6-E7 and the ventral one is evident by E8. Hence, the complete cytoarchitectony of the IO is well defined by approximately E8-E9.

We first detected neurons strongly expressing BEN mRNA in the region that contains the olivary primordium at E7 (Fig. 2A), 


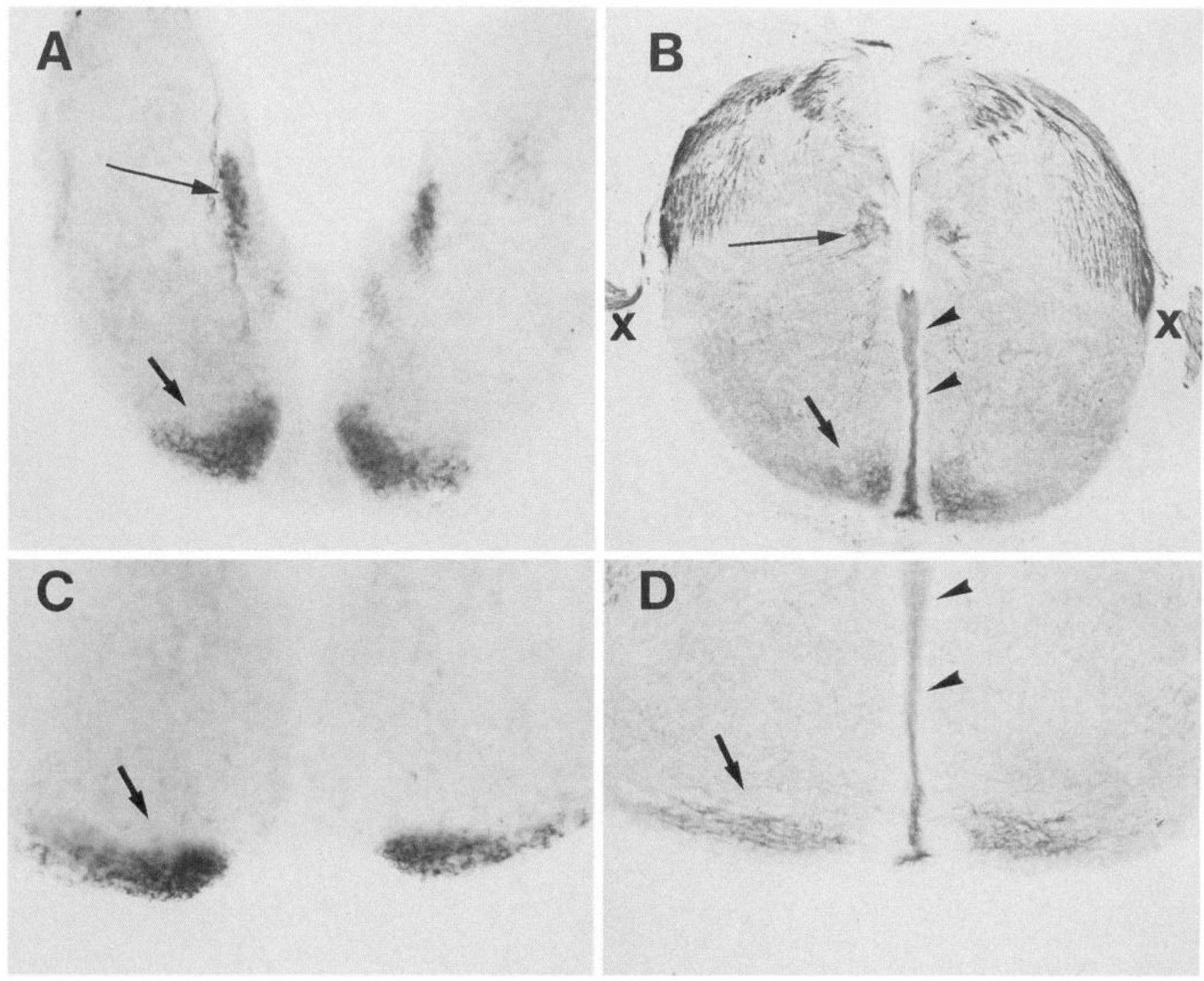

Figure 2. BEN expression in coronal sections through the inferior olivary primordium of E7-E8 chick embryos. The vibratome sections in $A$ (E7) and $C$ (E8) have been hybridized with a digoxigenin-labeled BEN probe. $B(\mathrm{E} 7.5)$ and $D(\mathrm{E} 8)$ illustrate areas similar to $A$ and $C$, respectively, which have been immunostained with anti-BEN antibodies. IO neurons (thick arrows) have finished their circumferential migration and have reached the floor plate, which is also labeled by BEN in its most medial portion (arrowheads in $B$ and $D$ ). The hypoglossal nucleus (long arrow in $A$ and $B$ ) and vagus nerves ( $\boldsymbol{x}$ in $B$ ) also express BEN. Magnification: $A, 50 \times ; B, 45 \times ; C, D, 70 \times$.

whereas BEN-IR neurons did not appear before E7.5-E8 (Fig. $2 B, D)$. From this stage on, the staining patterns for BEN proteins and BEN mRNA were identical in the IO (Fig. 2), but their intensity increased progressively and peaked at approximately E12-E13. In addition, the size of the IO also increased continuously between E7 and hatching (compare Figs. 2 and 3).

To determine whether BEN is expressed by all IO neurons, we stained alternate sections with cresyl violet and BEN antibodies and compared these series of sections with those of a younger embryo processed with radioactive BEN riboprobes (see Fig. 3). This comparison revealed that a large portion of the IO does not express BEN: only the caudal part of the dorsal accessory olive (DAO) and the ventral portion of the medial accessory olive (MAO), both belonging to the dorsal lamella, were positive for BEN (see Figs. 3, 4). Moreover, BEN expression in these IO neurons was transient, disappearing by hatching. During the whole period of expression, BEN remained confined to the same subsets of neurons (compare Figs. $2 C, D, 3 A, I$ ). BEN therefore appears to be a marker of IO biochemical heterogeneity.

\section{BEN expression in the developing cerebellum}

\section{E7-E10}

In the chick embryo, PCs arise between the third and sixth day of development (Hanaway, 1967; Feirabend et al., 1985), and the external granular layer (EGL) is visible from E6. By E7-E8, the cerebellar lamella is still unlobulated and, in addition to an EGL, it consists of ventricular, mantle, and marginal zones (see references in Feirabend, 1990) (Fig. 5A). From E9-E10, a multilayered $\mathrm{PC}$ plate as well as a molecular layer are recognizable (Fig. $5 B-D$ ) and according to Feirabend (1990), deep cerebellar nuclei have reached their adult location and configuration.

The earliest immunostaining with anti-BEN antibodies appeared by E7-E8 (Fig. $5 A$ ). From this stage to E10, BEN expression occurs mainly as two sagittally arranged stripes (one on each 

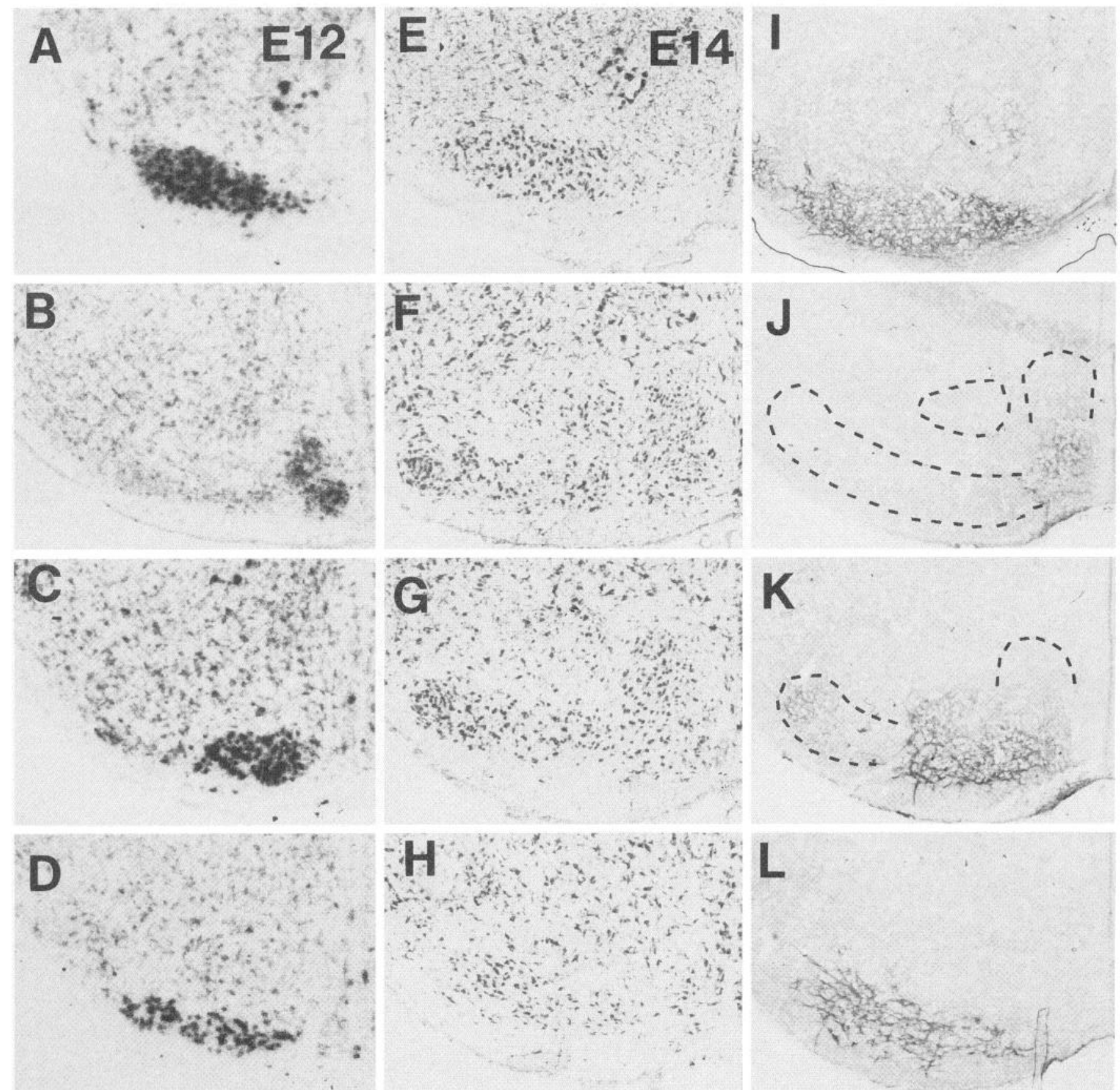

Figure 3. Micrographs of coronal cryostat sections through the right IO of E12 $(A-D)$ and $\mathrm{E} 14(E-L)$ chick embryos. In the left column, sections have been hybridized with a radioactive BEN probe, counterstained with toluidine blue, and photographed under bright-field illumination. Middle and right columns represent serial sections from an E14 embryo counterstained with cresyl violet-thionine $(E-H)$ or immunostained with anti-BEN antibodies $(I-L)$. Note the correspondence between BEN-immunoreactive and BEN mRNA-expressing IO subdivisions, and that BEN is only expressed in subsets of IO neurons. Magnification: $A-E, 60 \times ; F-O, 50 \times$.

cerebellar lamella) of strong immunostaining. These BENpositive symmetrical stripes extended from the inner mantle zone to the developing PC plate, stopping abruptly under the EGL (Fig. $5 A, B, D$ ). The structural elements expressing BEN-IR appeared as a dense meshwork, in which distinction between cell bodies and axons was virtually impossible. A faint diffuse BEN immunostaining also existed over broader areas of the cerebellar plate, in the presumptive white matter (Pourquié et al., 1992b). In addition, from E8.5 we found a BEN expression to occur in the deep nuclei.
Using nonradioactive in situ hybridization on cerebellar slabs, we detected a low expression of BEN mRNA around E7 in the inner mantle zone (not shown). Furthermore, from E8.5 BEN mRNA was detected in the deep nuclei and in two stripes within the PC plate (Fig. 5C).

Because our DiI axonal tracing experiments revealed that only a few axons of extracerebellar origin were present in the cerebellum before $\mathrm{E} 9$, and because the number and localization of the cortical stripes expressing BEN mRNA and BEN glycoprotein were identical (compare Fig. 5C,D), our observations suggested 


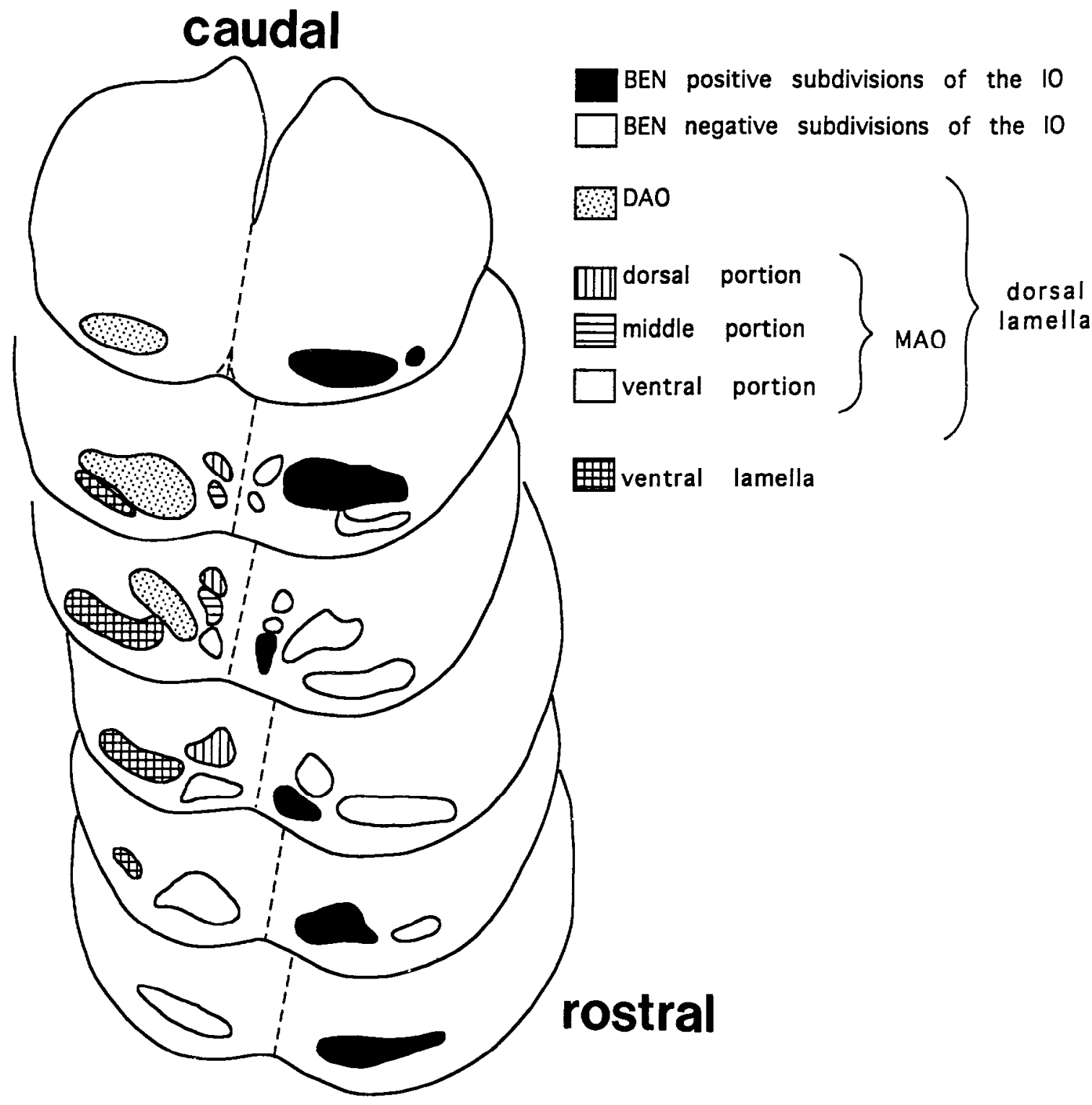

Figure 4. Schematic representation of the BEN-positive $\mathrm{IO}$ compartments in the chick embryo. The same subdivisions are labeled from E9 to hatching. The ventral lamella and the dorsal and medial portions of the MAO never express BEN. DAO, Dorsal accessory olive; $M A O$, medial accessory olive.

that in the E7-E10 chick cerebellum BEN-IR is essentially intrinsic to the cerebellum and is likely to result from its expression by a subset of PCs and most of the deep nuclear neurons (see below and Discussion).

\section{E11-E14}

During this period of intense cerebellar growth and development, there was a first stage (E11, E12) in which BEN-IR and BEN mRNA expression increased continuously. In the deep nuclei, most of the neurons expressed both the messenger and the protein (Fig. 6A,C,D). In the cerebellar cortex, BEN expression was still confined to parasagittal stripes. They were now more numerous, and two classes of stripes could be identified (Fig. 6). Those of the first class were intensely stained and abutted the inner limit of the EGL and contained both BEN mRNA and BEN protein (Fig. 6). The second class of stripes were larger, moderately stained, and ended at the interface between the PC plate and the developing inner granular layer. This second class of stripes lacked BEN mRNA (Fig. 6A,D).
The second stage of this period comprising E13 and E14 is characterized by the maximum expression of BEN glycoprotein. The two classes of stripes reported above were still present (Fig. $7 A, C, D$ ). In first-class stripes (Fig. $7 C$ ), BEN staining was very dense, somewhat hiding the cellular elements labeled by the antibody. This staining filled almost entirely the PC and the nascent molecular layer, reaching the lower limit of the EGL. Despite the intense staining, the apical dendritic arbors of PCs were identified at the superficial limit of the stripe, corresponding to the narrow band of nascent molecular layer (Fig. 7C, inset). The remaining elements with high $\mathrm{BEN}$-IR were confined to the $\mathrm{PC}$ layer, at this age approximately two to three cells deep. The difficulties in identifying $\mathrm{PC}$ bodies resulted from the simultaneous immunostaining of PCs and their climbing fibers, which at this developmental stage were in their phase of pericellular nests (see below). In stripes of the second class (Fig. 7A,D), BEN-IR elements appeared as fibrous structures with much less staining density, demarcating a thinner band located between the IGL and 


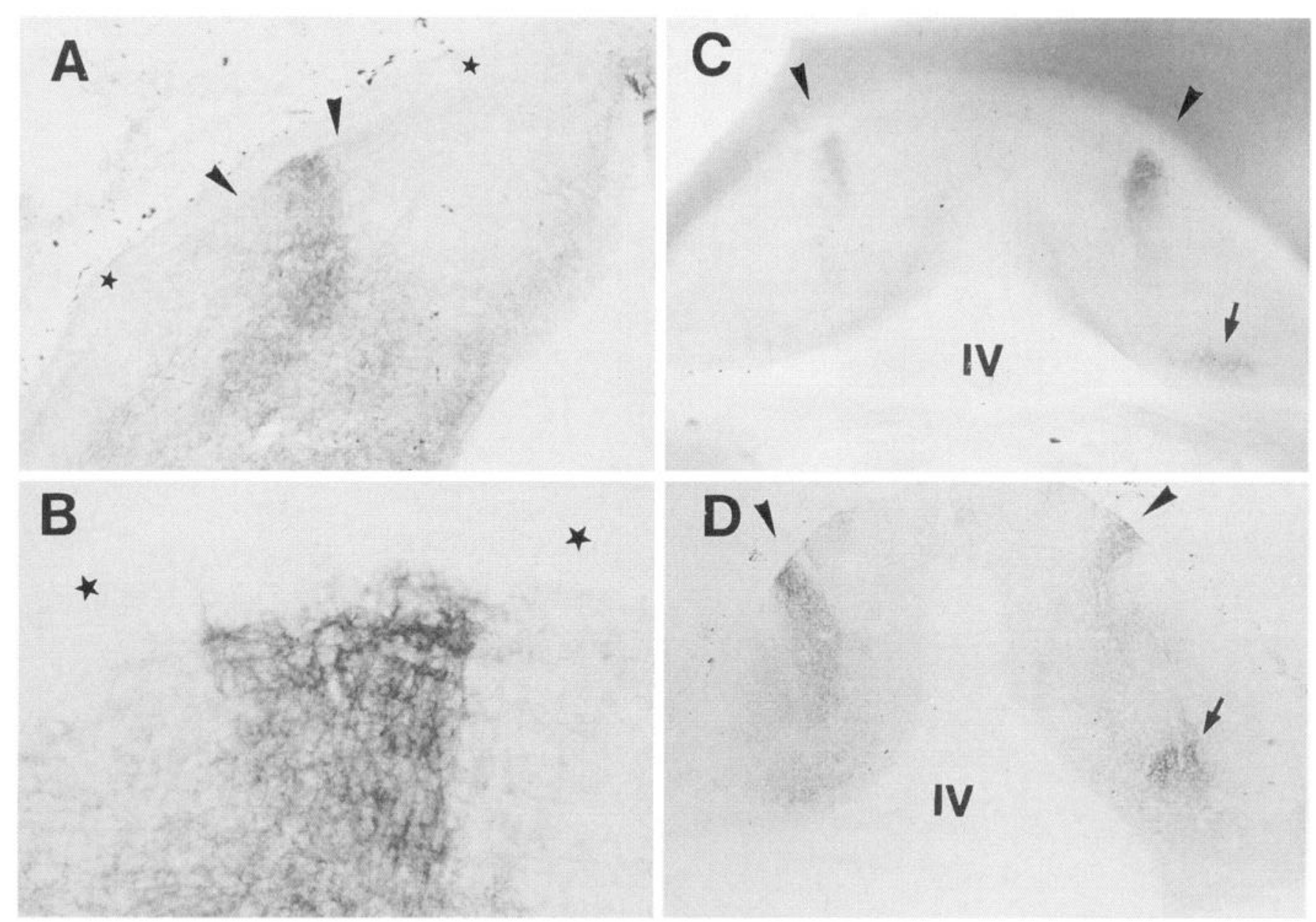

Figure 5. Early stages of BEN expression in the cerebellum. A, Coronal cryostat section of a hemicerebellum of an E7.5-E8 chick embryo immunostained with anti-BEN antibodies. Diffuse staining is observed throughout the cerebellum, but one sagittal stripe of cortex is more strongly stained (between arrowheads). The staining stops abruptly below the EGL (stars). B, Higher magnification of a BEN-immunopositive cerebellar stripe, in an E9 cerebellum. The stars in $B$ mark the EGL. $C$ and $D$ illustrate the correspondence between the BEN-immunopositive stripes at E10 (arrowheads in $D)$ and the stripes expressing BEN mRNA at E9 (arrowheads in $C$ ). Deep nuclei (short arrow in $C$ and $D$ ) also express both BEN mRNA and antigens. The white matter is faintly labeled. $I V$, Fourth ventricle. Magnification: $A, 70 \times ; B, 130 \times ; C$ and $D, 30 \times$.

the nascent molecular layer. In other words, these stripes occupied the cortical zone corresponding to the deeper half of the PC layer, as corroborated in double-labeled preparations, with antiBEN and anti-calbindin antibodies (Fig. $7 A, B$ ). Calbindin is selectively expressed by PCs in the chick cerebellum (Rogers, 1989). Moreover, in these preparations, the BEN-IR fibrous elements resembled climbing fibers in their pericellular nest stage (Ramón y Cajal, 1890), wrapping PC bodies, particularly at their basolateral poles. The identification of climbing fibers in their pericellular nest stage was possible in coronal (Fig. 7A) and in sagittal sections (Fig. 7D).

Both classes of stripes were continued, deeper in the cerebellar parenchyma by dense fibrous plexuses that spread within the underlying inner granular layer and white matter, confirming the occurrence of climbing fibers in all the BEN-IR stripes. Here again comparison of sections processed for in situ hybridization or immunostaining (Fig. 7E,F) confirmed that the stripes of the first class are the only ones to contain PCs expressing BEN mRNA. These PC stripes were found to be more numerous in the nodulus and uvula (Fig. $8 A$ ), forming the vestibulo-cerebellum and were not present in all vermal lobules. At E14, when BEN expression reached its peak, there was a maximum of BEN-IR stripes, which covered approximately half of the vermal cortex. We selected this age to analyze three-dimensionally the distribution of BEN-IR stripes in the embryonic chick cerebellum, without distinguishing between the two categories of stripes (Fig. 8). BEN-IR stripes were seen to be restricted to the foliated cortex, were symmetrical, and had a simple pattern reproducible from individual to individual. We identified four major BEN-IR stripes in the chick cerebellum, called them CF (for climbing fiber, see below), and numbered them from 1 to 4 , beginning at the midline (Fig. $8 B$ ). CF1 and CF2 extend the entire length of the cerebellum, except in lobules I and II, where CF2 is absent, because it has probably joined to CF1. CF1, the widest stripe, is almost adjacent to the midline. $\mathrm{CF} 3$, the smallest stripe, is observed laterally to $\mathrm{CF} 2$ exclusively in lobules X and IXc (only in their ventral portion), and in VI and IV. The last stripe, CF4, runs close to the border between foliated and nonfoliated cortices and can be followed throughout all the cerebellum, except in lobules IXa, b, VIII (ventrally), and I.

\section{E15 to adult}

From E14 onward BEN immunoreactivity and BEN mRNA expression decreased rapidly in first class stripes, such as by E16 PCs 

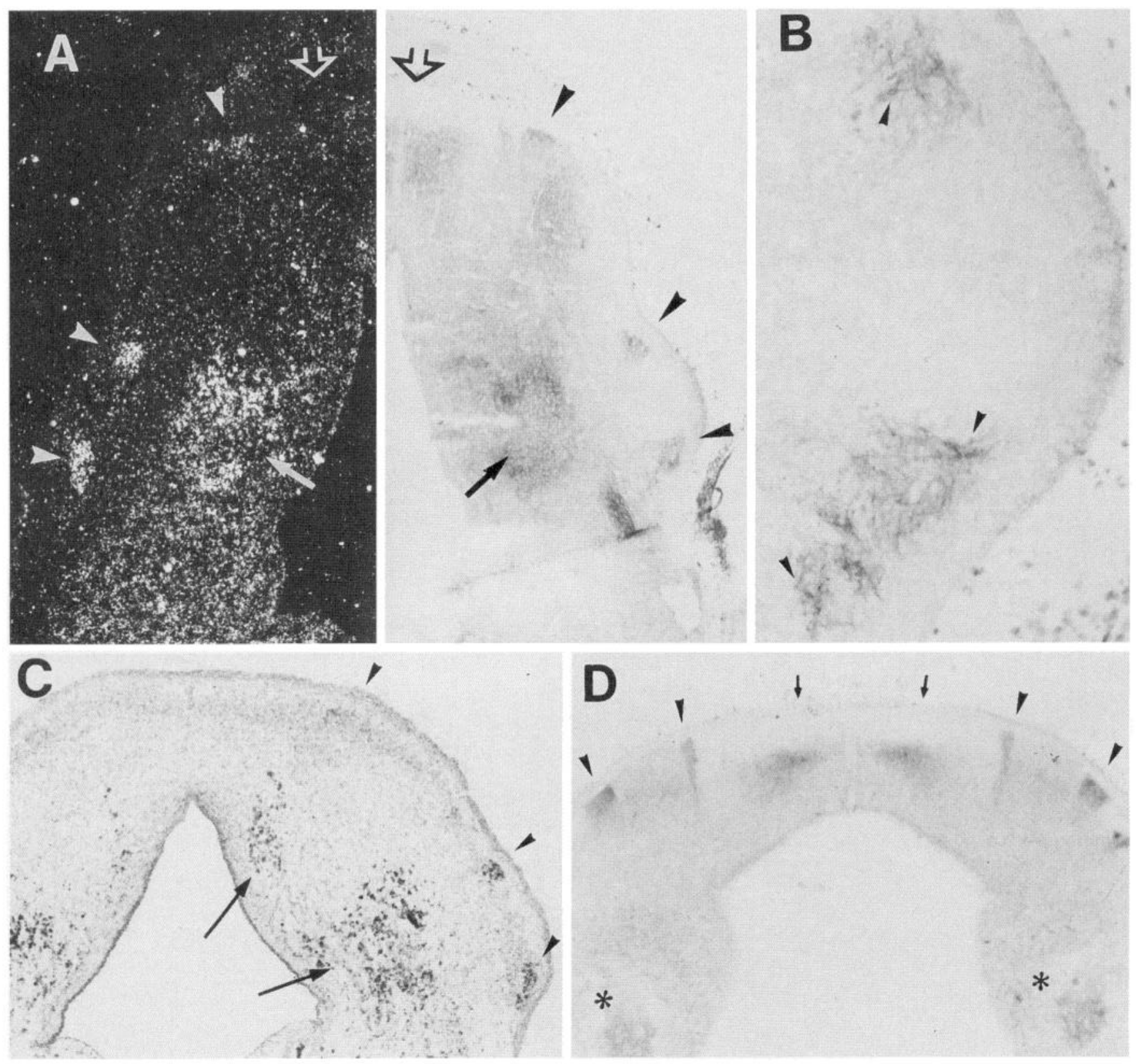

Figure 6. Micrographs of coronal sections from cerebella of E11 $(A, B), \mathrm{E} 11.5(C)$, and $\mathrm{E} 12(D)$ chick embryos, immunostained or hybridized with BEN. $A$ is a composite micrograph from two serial sections. The cerebellum has been hybridized with a radiaoctive-BEN probe (left portion of the micrograph, taken under dark-field illumination) or immunostained with anti-BEN antibodies (right portion). The deep nuclei (short arrow) and three lateral stripes in the Purkinje cell layer (arrowheads) express both BEN mRNA and BEN antigen. One more medial stripe (open arrow), which is also more diffuse, expresses only BEN antigen. $B$, Higher magnification of the small lateral stripes of cerebellar cortex, at E11, immunostained with BEN. Note in the Purkinje plate, the labeled profiles resembling dendrites and fusiform cell bodies (arrowheads). $C$, Bright-field illumination of the cerebellum, of an E11.5 embryo, hybridized with a radioactive BEN probe, and counterstained with toluidine blue. Three stripes in the PC layer (arrowheads), as well as most deep nuclear neurons (arrows), are expressing BEN mRNA. D, Coronal sections of an E12 cerebellum, immunostained with anti-BEN antibodies. Two types of stripes are observed: some are thin, strongly labeled, and reach the external granular layer (arrowheads), whereas others have a more diffuse and fibrous appearance (arrows). The deep nuclei are also labeled (asterisk). Magnification: $A, C, 40 \times ; B, 145 \times ; D, 35 \times$.

did not express BEN mRNA anymore. Nevertheless, BEN-IR fibers where still detected at E16 in first-class stripes, and their morphology was similar to those of the BEN-IR fibers observed in second-class stripes. These BEN-IR fibers, although still surrounding the PC bodies, began to cover the proximal segment of the ascending stem dendrites (Fig. 9). Therefore, they were climbing fibers in the transition between the "pericellular nest" and "capuchon" stages.
In conclusion, by E16 the number and position of the BEN-IR stripes was unchanged in comparison with previous stages, but first-class stripes were virtually indistinguishable from secondclass stripes. In addition, the presence at E16 of BEN-IR climbing fibers in stripes where BEN-expressing PCs were encountered earlier confirms that BEN is simultaneously expressed by climbing fibers and PCs in the BEN-IR first-class stripes.

In the following days, as reported previously by Pourquié et al. 

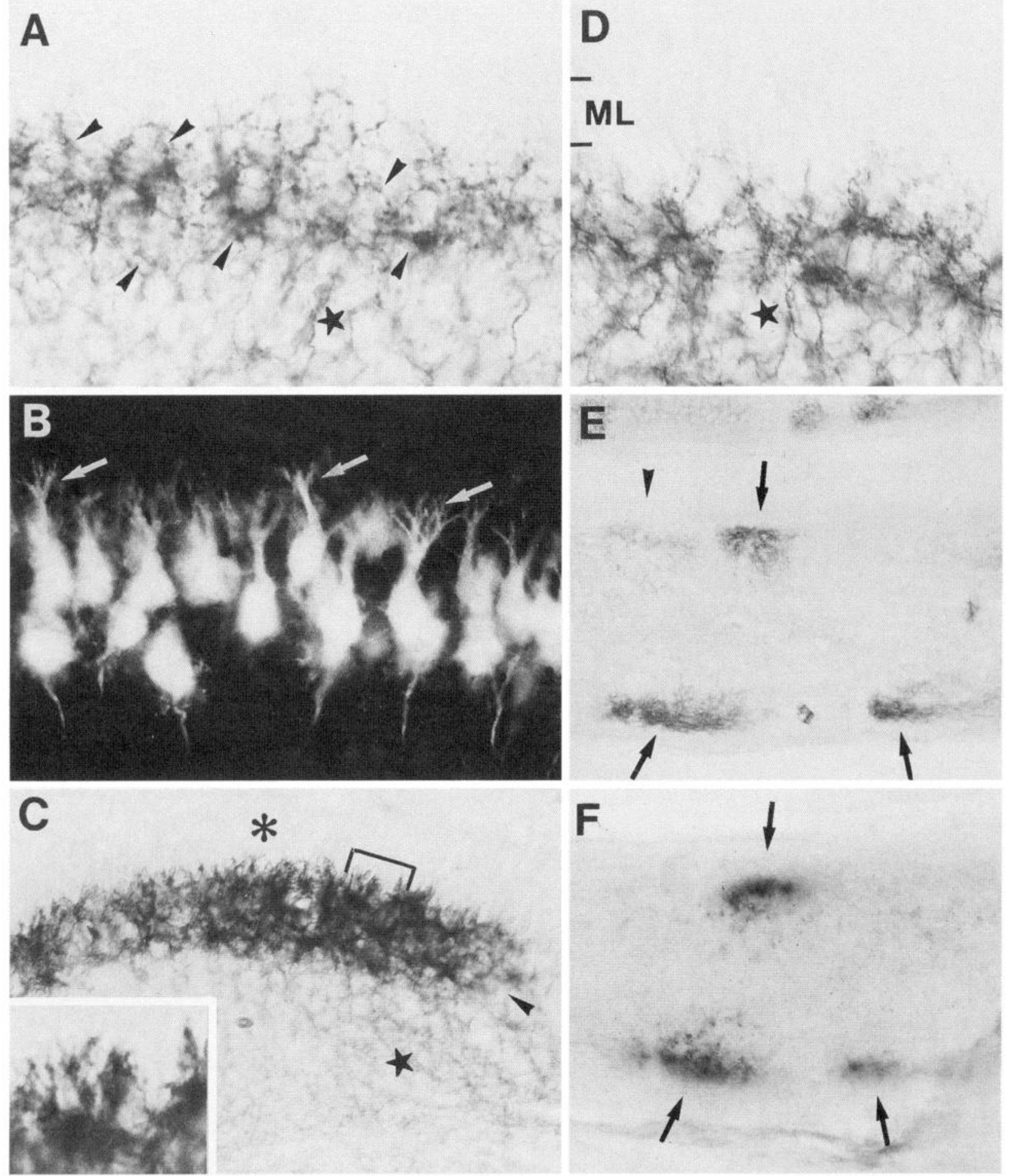

Figure 7. Expression of BEN in the cerebellar cortex of E14 chick embryo. $A$ and $B$ illustrate, in a coronal section of a double-immunolabeled preparation, a stripe of the second class. BEN-IR climbing fibers are forming their characteristic pericellular nests $(A)$ around the PC bodies $(B)$, visualized with anti-calbindin antibodies. Note that despite the presence of apical dendrites in the PCs (arrows in $B$ ), the climbing fibers (arrowheads in $A$ ) remain confined around the PC bodies, particularly their basal poles. This lack of somato-dendritic translocation at E14 is corroborated in sagittal sections $(D)$, in which the vast majority of BEN-IR climbing fibers do not enter the nascent molecular layer $(M L)$. The micrograph in $C$ illustrates the first category of stripes. The BEN immunostaining is much denser than in second-class stripes, filling almost completely the PC and nascent molecular layers, but stopping at the EGL (asterisk). Note that this staining occurs in the dendritic arbors of developing PCs (marked zone and its higher magnification at the inset), which still do not receive climbing-fiber innervation, because-as shown in $A$ and $D$-this innervation is in its pericellular nest stage. In both types of stripes $(A, C, D)$, many fibers are observed in the white matter (not shown) and developing IGL (stars). The arrowhead points to the border of the stripes. $E, F$, Coronal sections at the level of lobule $\mathrm{X}$ immunostained with anti-BEN antibodies $(E)$ or hybridized with a BEN probe $(F)$. In both instances, the staining follows a band-like pattern, but in $E$ two kinds of bands are observed: some are lightly stained (arrowhead), whereas the others are more densely stained (arrows). The latter are localized at identical positions than the PCs' stripes expressing BEN mRNA (first-class stripes). Magnification: $A, B, D, 520 \times ; C, 230 \times ;$ inset, $650 \times ; E, F, 90 \times$. 

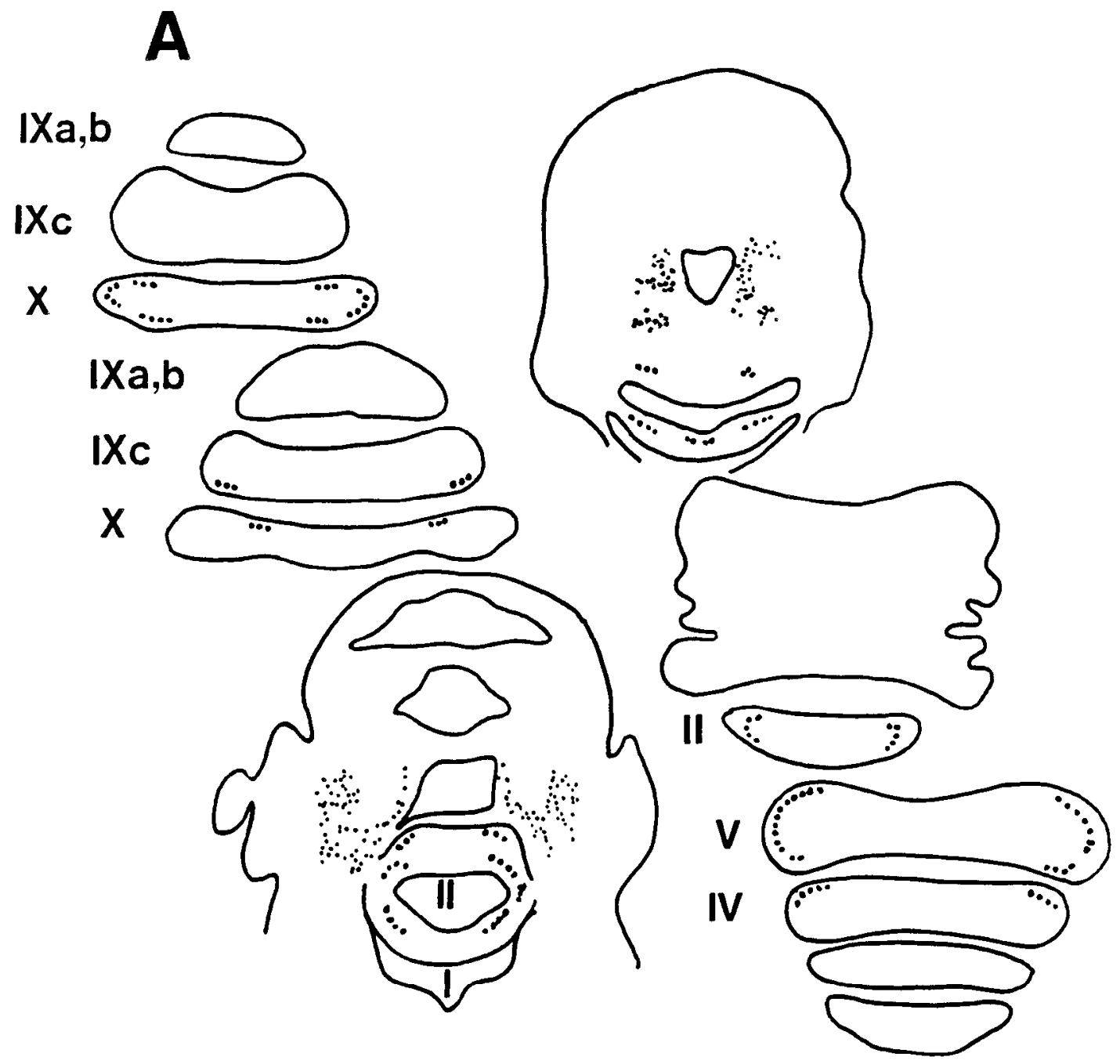

B
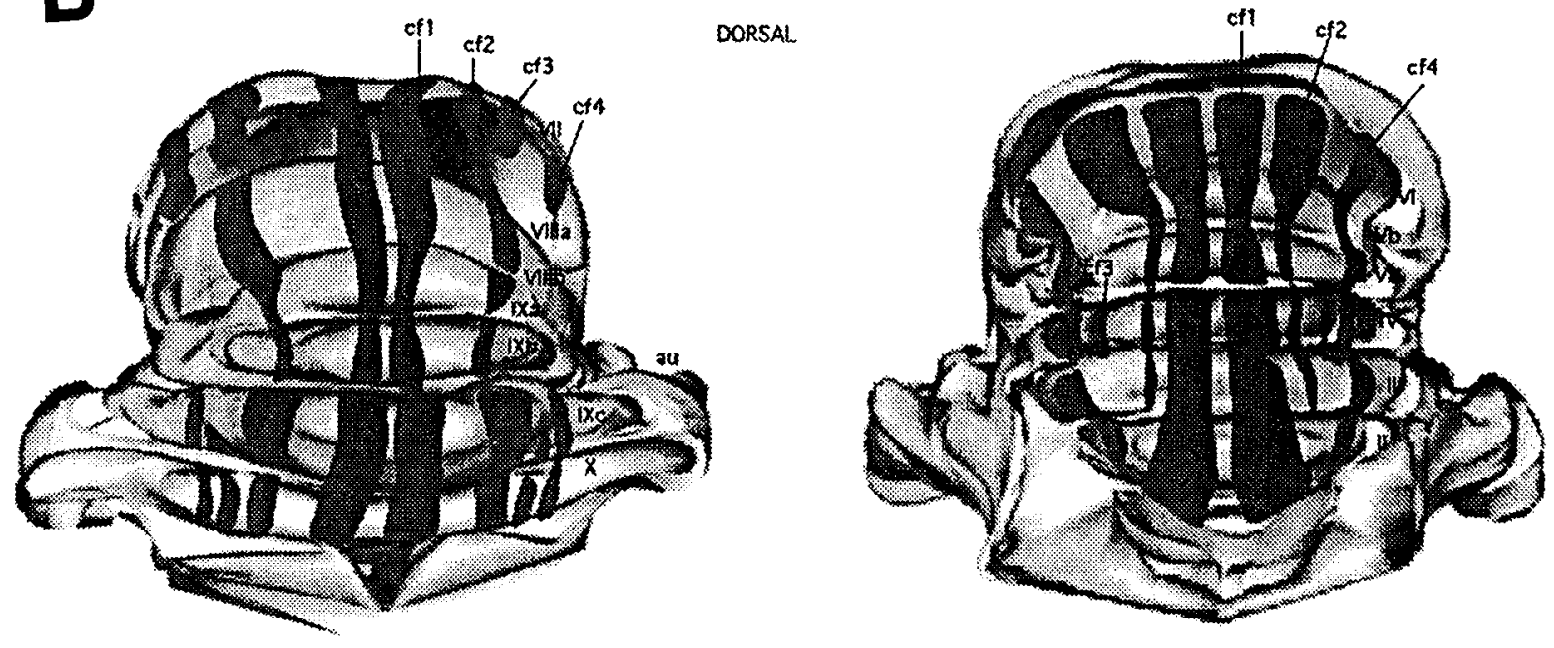

VENIGAL

Figure 8. A, Schematic representation of camera lucida drawings of coronal sections of E14 chick embryo hybridized with a radioactive BEN probe. The dotted regions correspond to the localization of PC stripes expressing BEN mRNA, in which BEN-IR climbing fibers also end. Note that they are not found in all lobules and are more numerous in the vestibulo-cerebellum. Vermal lobules are numbered with roman numerals. B, Three-dimensional reconstructions of the pattern of BEN-IR stripes in the cerebellum of an $\mathrm{E} 14$ chick embryo, in posterior and anterior views. 

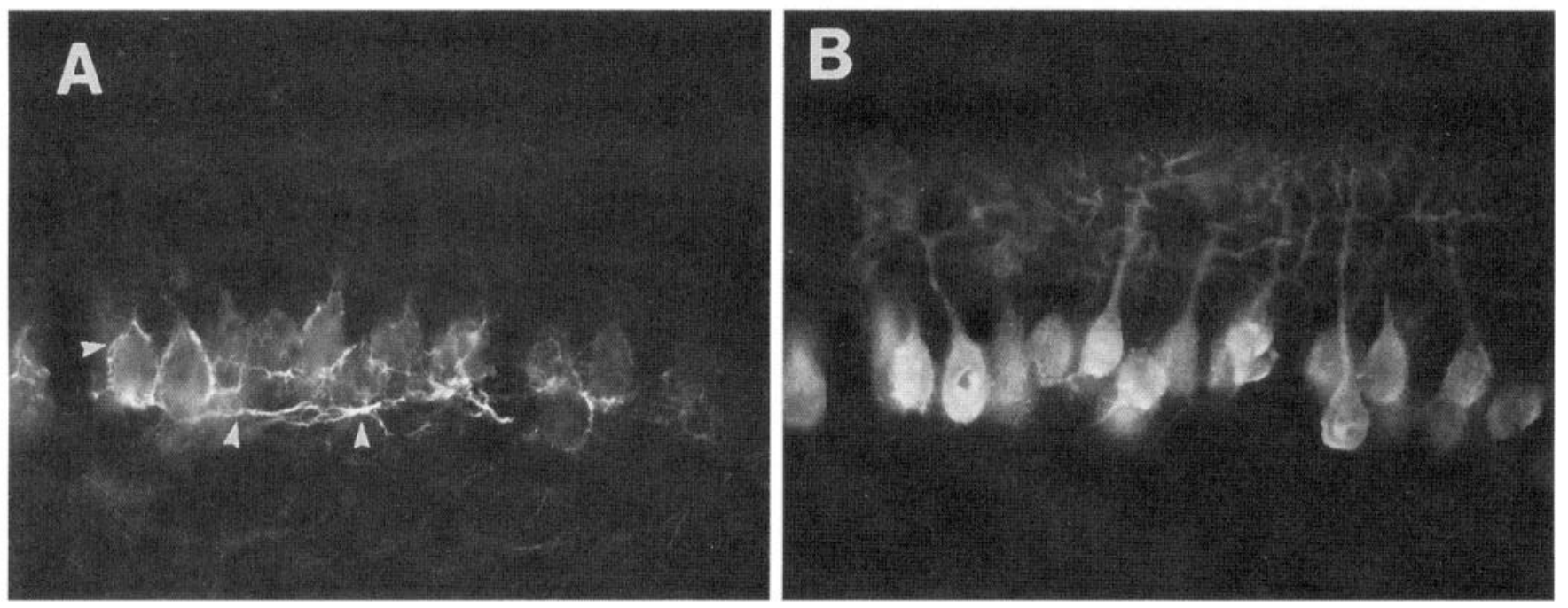

Figure 9. High magnification of a coronal section through the cerebellum of an E16 chick embryo double-immunostained with BEN $(A$, FITC) and CaBP $(B$, Texas red). BEN-IR climbing fibers (arrowheads in $A$ ) are at a transition between the pericellular nest and the capuchon. Purkinje cells (in $B$ ) are almost forming a monolayer and have developed dendritic trees. Magnification: $A, B, 155 \times$.

(1992b), BEN expression further decreased in the cerebellum, although deep nuclei still expressed a low level of BEN mRNA by hatching. The cerebellum of the adult chick was completely unlabeled by $\mathrm{BEN}$ antibodies and BEN probe.

\section{BEN expression in organotypic cultures of embryonic cerebella}

Besides using the timing data obtained with axonal tracing methods, we further used an in vitro approach to demonstrate that the expression of BEN by cerebellar neurons is independent of the influence of extracerebellar afferent fibers.

Cerebellar anlagen were put into cultures before the arrival of IO axons (E6.5-E7), and maintained in vitro for 4-40 d (Fig. $10 \mathrm{~A}$ ). The explants followed their own development and evolved into a cerebellar structure, with a foliated peripheral cortex and a central mass containing the deep nuclear neurons. Figure $10 B$, taken from one of these explants immunostained by calbindin antibodies after $15 \mathrm{~d}$ in vitro, illustrates the location of PCs, their axons, and the deep cerebellar nuclei. After a week in vitro, BEN-IR neurons were always detected in the explants (Fig. $10 C, E)$. These appeared to be clustered either at the periphery, corresponding to the cerebellar cortex, or deeply in the explant where they most probably belong to deep nuclear neurons. Double-labeling experiments combining BEN and calbindin antibodies were performed after several periods in vitro. Patches of calbindin/BEN double-labeled neurons, mainly located at the periphery of the explants, were systematically found (Fig. $10 C-F$ ). These observations provide evidence that PCs do express the BEN glycoprotein. Nevertheless, as observed in vivo, most of the calbindin-IR neurons-that is to say most PCs-were not immunoreactive for BEN.

Finally, we found that the expression of BEN by cerebellar neurons is transient; even though many calbindin-positive PCs still appeared in cerebellar explants after $30 \mathrm{~d}$ in vitro BEN-IR was not longer present (not shown).

\section{DISCUSSION}

To evaluate the presumptive role of BEN in the formation of the olivocerebellar projection, and to extend previously published results (Pourquié et al., 1992b), we have performed the study of the spatio-temporal distribution of BEN expression in the chick embryo using a combination of approaches: immunocytochemistry, in situ hybridization and organotypic cultures. The obtained results have shown the following.

First, in the IO, BEN expression begins as soon as E7, and therefore earlier than originally thought (Pourquié et al., 1992b). Second, from E8 cerebellar projecting neurons, PCs and deep nuclear neurons, which are the targets of olivary axons also express BEN. Moreover, both olivary and cerebellar expression are transient and disappear in the posthatched chick. More importantly, only a subset of IO neurons and of PCs express BEN. Finally, in the cerebellar cortex, BEN-expressing elements are distributed in sagittally oriented stripes, which follow a precise spatio-temporal pattern of expression. Two types of stripes are encountered; one type is composed of PCs and climbing fibers, both expressing BEN, whereas the other contains only BEN-IR climbing fibers. Complementary experiments, using axonal tracing methods in fixed embryos and in vitro analysis of BEN expression in isolated cerebellar explants, have allowed us to conclude that $\mathrm{BEN}$ is expressed in an autonomous manner, independently of olivocerebellar interactions. Thus, BEN appears as excellent candidate for a "target recognition molecule" implicated in the formation of this projection map.

\section{In the inferior olive, BEN is a marker of neuronal heterogeneity}

Part of the novel information reported here is that BEN is transiently and selectively expressed by only subsets of IO neurons. Thus, from E7 to the newly hatched chick, the BENexpressing neurons were located solely in the DAO and ventral MAO (according to the nomenclature of Vogt-Nilsen, 1954; later corroborated by Furber, 1983, and by Arends and Voogd, 1989).

These observations are reminiscent of the transient biochemical compartmentalization of the IO described in the rat (Wassef et al., 1992a) and confirm that during development, small groups of IO neurons can be individualized by their biochemical properties. Moreover, from all the known cell adhesion molecules expressed by IO neurons, such as N-CAM (Daniloff et al., 1986) and TAG1/Axonin 1 (Wolfer et al., 1994), only BEN is expressed by a 

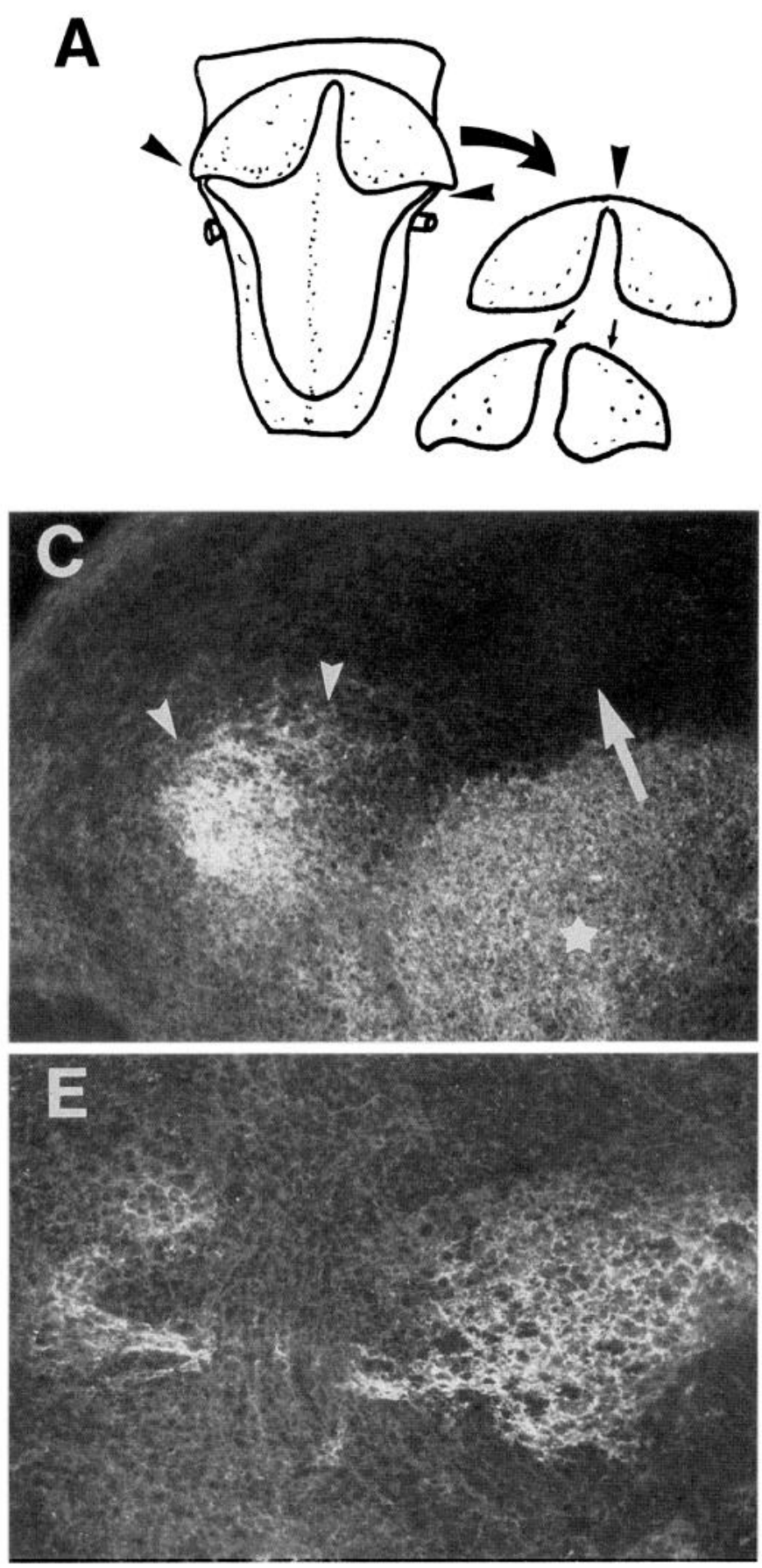
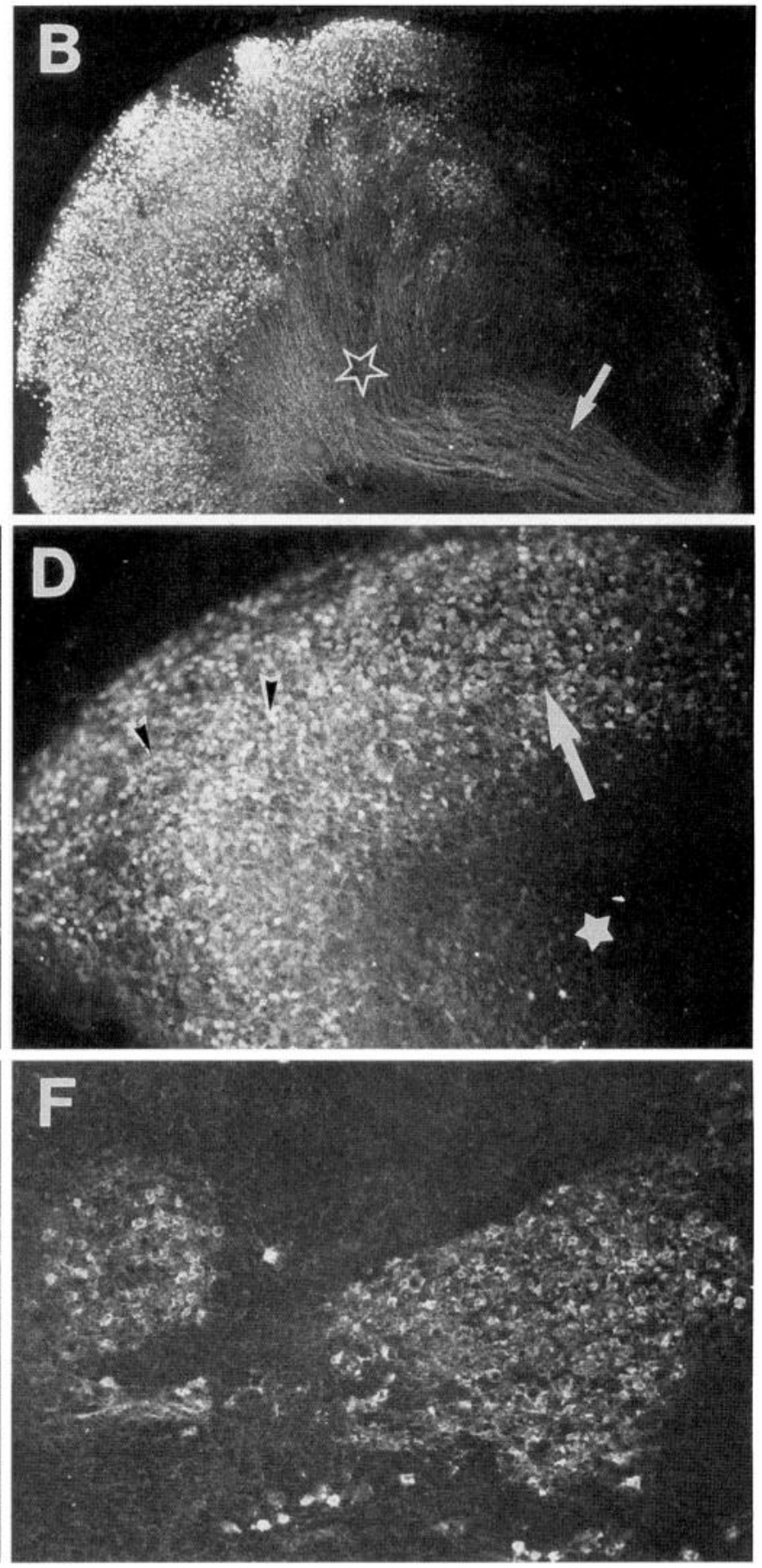

Figure 10. Organotypic culture of isolated embryonic cerebella. A, Schematic drawing illustrating the morphology of the hindbrain of E6-E8 chick embryos, and the obtention of the cultured piece of hemicerebellum. $B$, Low magnification of the whole-mount left half of an E7 isolated hemicerebellum cultured for $15 \mathrm{~d}$ and immunostained with CaBP (FITC). Purkinje cell axons converge to the deep nuclei region (star), but some of them have grown further forming a wide fascicle (arrow). $C$ and $D$, Whole-mount explants of E6.5 cerebella cultured for $8 \mathrm{~d}$ and immunostained with BEN ( $C$, FITC) and $\mathrm{CaBP}(D$, Texas red). A patch of CaBP-positive PCs (arrowheads in $D$ ) is also BEN-immunoreactive (arrowheads in $C$ ). Nevertheless, most of the PCs are only CaBP-positive (arrows in $C$ and $D$ ), and a large portion of the BEN immunoreactivity is not colocalized with $C a B P(s t a r$ in $C$ and $D$ ). $E, F$, High magnification of a cryostat section through an isolated cerebellar explant of E7.5 chick embryo cultured for $7 \mathrm{~d}$ and double-immunostained with BEN $(E$, FITC) and $\mathrm{CaBP}(F$, Texas red). In this case, all CaBP-positive PCs appear to express BEN. Magnification: $B, 35 \times ; C, D, 70 \times ; E, F, 140 \times$.

subpopulation of these neurons. BEN appears, therefore, as a neuronal marker of subpopulation-type identity within the IO, and this differential BEN expression is a strong argument for the postulation that BEN plays a key role in the formation of the olivocerebellar projection (see below).

\section{BEN is expressed by climbing fibers}

Several lines of evidences have been reported in this study to support our proposition that BEN is expressed by climbing fibers. First, the intrinsic features of the stained axons which correspond to those of climbing fibers in their pericellular nest stage. Second, 
the synchrony between the arrival of IO axons to the Purkinje plate and the appearance of BEN-IR fibers' stripes. Third, the topographic parasagittal arrangement of the latter and its relation to the known topography of the adult avian olivocerebellar projection (Freedman et al., 1977; Arends and Voogd, 1989). For instance, the auricles that are devoid of BEN-IR fibers receive projections from BEN-negative olivary regions (medial and dorsal portions of the medial cell column).

\section{BEN is also transiently expressed by clusters of PCs}

We have shown here that, during the development of the chick cerebellum, a subset of PCs transiently expresses BEN. This observation rejoined a number of studies, particularly those in rodents, indicating that postmitotic PCs have intrinsic biochemical properties and that the cerebellar cortex is parceled into broad compartments (Wassef and Sotelo, 1984; Wassef et al., 1985) (for reviews, see Sotelo and Wassef, 1991; Hawkes and Mascher, 1994). But BEN appears unique in comparison with all other PC biochemical markers.

First, BEN as a cell adhesion molecule, may be involved in the process of cell surface recognition (Pourquié et al., 1992b) whereas the other rodent's markers (calcium binding proteins, glycoproteins, protein kinases, etc.; see Sotelo and Wassef, 1991) are not (Wassef et al., 1985, 1992a).

Furthermore, the spatio-temporal pattern of expression of BEN in PCs is unique: BEN is expressed by a small subset of PCs early in development, never involves all PCs, and disappears just after the beginning of climbing fiber/PC synaptogenesis. In rodents, the expression of PC markers was only known to occur according to two developmental patterns: the earliest expressed markers (calbindin comes at approximately E16 in the rat) appear first in small subsets of PCs, distributed into alternating sagittal clusters. As development proceeds, more and more PCs express these markers, and by postnatal day 5 (P5) the adult pattern in which all PCs are positive is attained (Wassef et al., 1985). Hence, the emergence of PC heterogeneity is the result of an asynchronous expression of these markers, which delimits transient biochemically defined zones in the cerebellar cortex (transient cerebellar compartmentation). The other type of markers (zebrins I and II) is characterized by a late onset of expression (P6 in the rat; see Hawkes et al., 1992), which rapidly involves all PCs (P12), and is later restricted to only a subset of PCs (around P30), revealing the adult pattern of sagittal parcellation.

All PCs are known to express other cell adhesion molecules such as N-CAM and Ng-CAM/L1 (Chuong et al., 1987), Thy-1 (Sheppard et al., 1988), and NrCAM/Bravo (Krushel et al., 1993), even during early development. Subsets of PCs express other antigens such as Strom-3 (Sharma et al., 1991), Big-1, and Big-2 (Yoshihara et al., 1994) or the epitope HNK-1 (Eisenman and Hawkes, 1993), but those whose development has been studied are detected too late in ontogenesis to be involved in the formation of the olivocerebellar projection.

\section{BEN expression in the IO and cerebellum arise independently}

To consider BEN as a "target recognition molecule" involved in the formation of the broad topography of the olivocerebellar projection, its expression should occur independently in both presynaptic (IO) and postsynaptic (PCs) neurons. This essential point has been verified in the present study.

First, the timing of the initial steps in the formation of the projection was elucidated with axonal tracing experiments, be- cause these data were not available. The results make it clear that IO axons enter the cerebellar parenchyma just before E9 and reach the Purkinje plate by E10. Because thc onsct of BEN expression in the olivocerebellar system occurs between E7 and $\mathrm{E} 8$, there is no doubt that at least the onset of this expression takes place in the absence of interactions between $\mathrm{IO}$ axons and their postsynaptic targets the PCs.

Second, the ability of some PCs to express BEN, in the E6.5 cerebellar explants kept in vitro for 4-30 d, indicates that extracerebellar fibers are not necessary to trigger BEN expression in PCs. Moreover, the spontaneous extinction of BEN-IR in the neurons of explants maintained for over $30 \mathrm{~d}$ in vitro reveals that such fibers are also unnecessary to turn off BEN expression in the cerebellum. This strongly suggests that BEN expression follows an intrinsic developmental program, independent of extrinsic factors. This is in agreement with previous observations concerning other markers of PC biochemical heterogeneity, the molecule zebrin I (Wassef et al., 1990) and the transgenic mice carrying the L7/lacZ hybrid gene (a PC specific transgene, Oberdick et al., 1990, 1993), which indicate that a genctic mcchanism is involved in the establishment of the compartmentation of the cerebellar cortex. It is then possible that the expression of BEN by a subset of PCs is also an intrinsic property of these neurons, providing them with a subpopulation-type identity.

\section{BEN as a target recognition molecule in the formation of the olivocerebellar projection}

$\mathrm{BEN}$ is not a pan-neuronal marker but is widely expressed in the CNS of the chick embryo, in discrete nuclei from the spinal cord to the forebrain (Tanaka and Obata, 1984; Pourquié et al., 1990, 1992a,b; Chang et al., 1992; Guthrie and Lumsden, 1992; Pollerberg and Mack, 1994; Simon et al., 1994; Chédotal et al., 1995) and in all those nuclei, BEN appears to be expressed by all neurons. Therefore, the pattern of BEN expression in the olivocerebellar system is unique, as BEN is only synthesized by subsets of IO neurons and PCs.

Previous work in developing rodent cerebellum (see Sotelo and Wassef, 1991), together with that reported here in the chick, suggests that cortical clusters of homogeneous PCs (named basic cortical compartments; Wassef et al., 1985) have distinctive membrane features that can be recognized by specific subsets of IO axons (emerging from ncurons in projcctional olivary compartments). We propose that the topographic organization of the olivocerebellar system might be achieved by matching subgroups of source and target neurons by a chemoaffinity mechanism slightly different from that postulated by Sperry (1963). In our proposition the matching occurs between groups of neurons, which provide the projection with broad organization, whereas in Sperry's hypothesis (1963) individual neurons, or even synapses, directly provide the projection with its ultimate fine-grained topography.

One intriguing result in this study is the incomplete matching between BEN expression in IO neurons and PCs. BEN is expressed in a much broader population of IO neurons than their PC targets, as evidenced by the occurrence of a sccond class of BEN-expressing stripes of climbing fibers in which, although with correct topographic localization, their PC targets do not express $B E N$. This observation raises the problem on the nature of $\mathrm{BEN}$ interactions during the formation of the olivocerebellar projection. In vitro cell aggregation experiments (Tanaka et al., 1991; El-Deeb et al., 1992; DeBernardo and Chang, 1995) indicate that BEN has selective homophilic interactions; therefore, for stripes 
of the first class, in which both the source and the target express $\mathrm{BEN}, \mathrm{BEN}$ could actually represent a recognition molecule playing this role through homophilic binding.

But what would be the role of BEN in stripes of second class? The first answer is that BEN does not play any role in target recognition in second class stripes, and our results could be compared with those recently published by Chiba et al. (1995) on the expression of fasciclin III (another cell adhesion molecule of the immunoglobulin superfamily) in the PNS of Drosophila embryos. During the formation of neuromuscular connections, afferent motor axons expressing fasciclin III outnumber the amount of target muscle cells also expressing this molcculc. In a situation in which fasciclin III is ectopically expressed on all muscles, only the fasciclin III-expressing motor axons that normally synapse with muscles expressing this molecule establish abnormal synapses, whereas the behavior of other fasciclin III motor axons remains unchanged. One possible explanation for these results could be the absence in these motor axons, as well as in the BENexpressing climbing fibers that synapse on BEN-negative PCs, of proteins involved in the transduction of the signal between those cell adhesion molecules and the growth conc machinery (Gumbiner, 1993). A second possibility is that BEN in climbing fibers of this sort may have heterophilic interactions with BEN negative PCs. BEN would bind a receptor molecule selectively expressed on corresponding PCs. Recently it has been shown in the human immune system that BEN is a ligand for CD6, a member of the scavenger receptor cystein-rich family of protein (Bowen et al., 1995). CD6 is expressed in the adult human brain (Mayer et al., 1990), but its localization in the developing brain has not yet been studied. In any case, whatever the nature of the interactions, BEN would be only one of the combination of cell surface molecules involved in the formation of the olivocerebellar projection.

In conclusion, the morphological results reported here have shown the occurrence of a precise spatio-temporal correlation between the expression of BEN mRNA and protein by subsets of IO neurons and PCs and the sequential steps followed by olivocerebellar fibers in the target invasion and map formation. This correlation, although compelling, is not enough to prove the functional implication of BEN. Experimental manipulations, using blocking antibodies or antisense mRNA, among others, are needed to provide a rigorous proof to the here advanced hypothesis. Nevertheless, this correlation is a prerequisite to ascribe to $\mathrm{BEN}$ the role of a recognition molecule involved in the formation of this projection map. It is worth noting that a similar role for this molecule has been proposed for the formation of the retinotectal projection (Pollerberg and Mack, 1994) and in the selectivity of motor neuron/muscle innervation (Simon et al., 1994). However, in these two cases although the projecting axons bear the BEN molecules, its presence in the postsynaptic partners is much less obvious.

\section{REFERENCES}

Arends JJA, Voogd J (1989) Topographical aspects of the olivocerebellar system in the pigeon. Exp Brain Res [Suppl] 17:52-57.

Armstrong RC, Clarke PGH (1979) Neuronal death and the development of the pontine nuclei and inferior olive in the chick. Neuroscience $4: 1635-1647$.

Azizi SA, Woodward DJ (1987) Inferior olivary nuclear complex of the rat: morphology and comments on the principles of organization within the olivocerebellar system. J Comp Neurol 263:467-484.

Baier H, Bonhoeffer F (1992) Axon guidance in vitro by a target-derived cell membrane component. In: The nerve growth cone (Letourneau PC, Kater SB, Macagno ER, eds), pp 195-206. New York: Raven.
Bally-Cuif L, Goridis C, Santoni MJ (1993) The mouse NCAM gene displays a biphasic expression pattern during neural tube development. Development 117:543-552.

Bowen MA, Patel DD, Li X, Mordrell B, Malacko AR, Wang WC, Marquardt $\mathrm{H}$, Neubauer M, Pesando JM, Francke U, Haynes BF, Aruffo A (1995) Cloning, mapping, and characterization of activated leukocyte-cell adhesion molecule (ALCAM), a CD6 ligand. J Exp Med 181:2213-2220.

Buisseret-Delmas C, Angaut P (1993) The cerebellar olivo-corticonuclear connections in the rat. Prog Neurobiol 40:63-87.

Burns FR, Von Kannen S, Guy L, Raper JA, Kamholz J, Chang S (1991) DM-GRASP, a novel immunoglobulin superfamily axonal surface protein that supports neurite extension. Neuron 7:209-220.

Chang S, Fan J, Nayak J (1992) Pathfinding by cranial nerve VII (facial) motorneurons in the chick hindbrain. Development 114:815-823.

Chédotal A, Pourquié O, Sotelo C (1995) Initial tract formation in the brain of the chick embryo: selective expression of the BEN/SC1/DMGRASP cell adhesion molecule. Eur IJ Neurosci 7:198-212.

Chiba A, Snow P, Keshishian H, Hotta Y (1995) Fasciclin III as a synaptic target recognition molecule in Drosophila. Nature 374:166-168.

Chuong C-M, Crossin KL, Edelman GM (1987) Sequential expression and differential function of multiple adhesion molecules during the formation of cerebellar cortical laycrs. J Ccll Biol 104:331-342.

Daniloff JK, Chuong CM, Levi G, Edelman GM (1986) Differential distribution of cell adhesion molecules during histogenesis of the chick nervous system. J Neurosci 6:739-758.

DeBernardo AP, Chang S (1995) Native and recombinant DM-GRASP selectively support neurite extension from neurons that express GRASP. Dev Biol 169:66-75.

Eisenman LM, Hawkes R (1993) Antigenic compartmentation in the mouse cerebellar cortex: zebrin and HNK-1 reveal a complex, overlapping molecular topography. J Comp Neurol 335:586-605.

El-Deeb S, Thompson SC, Covault J (1992) Characterization of a cell surface adhesion molecule expressed by a subset of developing chick neurons. Dev Biol 149:213-227.

Feirabend HKP (1990) Development of longitudinal patterns in the cerebellum of the chicken (Gallus domesticus): a cytoarchitectural study on the genesis of cerebellar modules. Eur J Morphol 28:169-223.

Feirabend HKP, Van Luxemburg EA, Van Denderen-Van Dorp $\mathrm{H}$, Voogd J (1985) A ${ }^{3} \mathrm{H}$-thymidine autoradiographic study of the development of the cerebellum of the White Leghorn (Gallus domesticus): evidence for longitudinal neuroblast generation patterns. Acta Morphol Neerl-Scand 23:115-126.

Freedman SL, Voogd J, Vielvoye J (1977) Experimental evidence for climbing fibers in the avian cerebellum. J Comp Neurol 175:243-252.

Fricdland DR, Eden AR, Laitman JT (1995) Naturally occurring motoneurone cell death in rat upper respiratory tract motor nuclei: a histological, fast DiI and immunocytochemical study in the hypoglossal nucleus. J Neurobiol 27:520-534.

Furber SE (1983) The organization of the olivocerebellar projection in the chicken. Brain Behav Evol 22:198-211.

Gumbiner BM (1993) Proteins associated with the cytoplasmic surface of adhesion molecules. Neuron 11:551-564.

Guthrie S, Lumsden A (1992) Motor neuron pathfinding following rhombomere reversals in the chick embryo hindbrain. Development 114:663-673.

Hamburger V, Hamilton HL (1951) A series of normal stages in the development of the chick embryo. J Morphol 88:49-92.

Hanaway J (1967) Formation and differentiation of the external granular layer of the chick cerebellum. J Comp Neurol 131:1-14.

Harkmark W (1954) Cell migration from the rhombic lip to the inferior olive, the nucleus raphe and the pons: a morphological and experimental investigation on chick embryos. J Comp Neurol 100:115-210.

Harkmark W (1956) The influence of the cerebellum on development and maintenance of the inferior olive and the pons. J Exp Zool 131:333-371

Hawkes R, Mascher C (1994) The development of molecular compartmentation in the cerebellar cortex. Acta Anat 151:139-149.

Hawkes R, Brochu G, Doré L, Gravel C, Leclerc N (1992) Zebrins: molecular markers of compartmentation in the cerebellum. In: The cerebellum revisited (Llinás R, Sotclo C, cds), pp 22-55. New York: Springer.

Holt CE, Harris WA (1993) Position, guidance, and mapping in the developing visual system. J Neurobiol 24:1400-1422. 
Krushel LA, Prieto AL, Cunningham BA, Edelman GM (1993) Expression patterns of the cell adhesion molecule Nr-CAM during histogenesis of the chick nervous system. Neuroscience 53:797-812.

Maycr B, Funkc I, Sccd B, Ricthmüllcr Wciss E (1990) Expression of CD6 $T$ lymphocyte differentiation antigen in normal human brain. J Neuroimmunol 29:193-202.

Oberdick J, Smeyne RJ, Mann JR, Zackson S, Morgan JI (1990) A promoter that drives transgene expression in cerebellar Purkinje and retinal bipolar neurons. Science 248:223-226.

Oberdick J, Schilling K, Smeyne RJ, Corbin JG, Bocchiaro C, Morgan JI (1993) Control of segment-like patterns of gene expression in the mouse cerebellum. Neuron 10:1007-1018.

Okado N, Yoshimoto M, Furber SE (1987) Pathway formation and the terminal distribution pattern of the spinocerebellar projection in the chick embryo. Anat Embryol 176:165-174.

Pinol MR, Kägi U, Heizmann CW, Vogel B, Séquier J-M, Haas W, Hunziker W (1990) Poly- and monoclonal antibodies against recombinant rat brain calbindin D-28K were produced to map its selective distribution in the central nervous system. J Neurochem 54:1827-1833.

Pollerberg EG, Mack TGA (1994) Cell adhesion molecule SC1/DMGRASP is expressed on growing axons of retina ganglion cells and is involved in mediating their extension on axons. Dev Biol 165:670-687.

Pourquié O, Coltey M, Thomas J-L, Le Douarin NM (1990) A widely distributed antigen developmentally regulated in the nervous system. Development 109:743-752.

Pourquié O, Corbel C, Le Caer JP, Rossier J, Le Douarin NM (1992a) BEN, a surface glycoprotein of the immunoglobulin superfamily, is expressed in a variety of developing system. Proc Natl Acad Sci USA 89:5261-5265.

Pourquié O, Hallonet MFR, Ie Douarin NM (1992b) Association of BEN glycoprotein expression with climbing fiber axonogenesis in the avian cerebellum. J Neurosci 12:1548-1557.

Ramón y Cajal S (1890) A propos de certains éléments bipolaires du cervelet avec quelques détails nouveaux sur l'évolution des fibres cérébelleuses. Int Mschr Anat 7:447 468 .

Rogers JH (1989) Immunoreactivity for calretinin and other calciumbinding proteins in the cerebellum. Neuroscience 31:711-721.

Sharma E, Beaudet A, Bambrick LL, Sullivan AK (1991) Expression of a marrow stroma and thymus-associated antigen (ST3) in the rat brain: a comparison with Thy-1. Brain Res 540:164-176.

Sheppard AM, Konopka M, Jeffrey PL (1988) The developmental appearance of Thy-1 in the avian cerebellum. Dev Brain Res 40:181-192.

Simon H, Guthrie S, Lumsden A (1994) Regulation of SC1/DM-GRASP during the migration of motor neurons in the chick embryo brain stem. J Neurobiol 25:1129-1143.
Sotelo C, Wassef M (1991) Cerebellar development: afferent organization and Purkinje cell heterogeneity. Philos Trans R Soc Lond [Biol] 331:307-313

Spencer R, Charman M, Armitage JS, Lawson DEM (1976) Production and properties of vitamin-D induced mRNA for chick calcium-binding protein. Eur J Biochem 71:399-409.

Sperry RW (1963) Chemoaffinity in the orderly growth of nerve fiber patterns and connections. Proc Natl Acad Sci USA 50:703-710.

Stoppini L, Buchs P-A, Muller D (1991) A simple method for organotypic cultures of nervous tissue. J Neurosci Methods 37:173-182.

Tan K, Le Douarin NM (1991) Development of the nuclei and cell migration in the medulla oblongata, application of the quail-chick chimera system. Anat Embryol 183:321-343.

Tanaka H, Obata K (1984) Developmental changes in unique cell surface antigens of chick embryo spinal motoneurons and ganglion cells. Dcv Biol 106:26-37.

Tanaka H, Matsui T, Agata A, Tomura M, Kubota I, McFarland KC, Kohr B, Lee A, Phillips HS, Shelton DL (1991) Molecular cloning and expression of a novel adhesion molecule, SC1. Neuron 7:535-545.

Vogt-Nilsen L (1954) The inferior olive in birds. J Comp Neurol 101:447-481.

Wassef M, Sotelo C (1984) Asynchrony in the expression of guanosine $3^{\prime}, 5^{\prime}-$ phosphate-dependent protein kinase by clusters of Purkinje cells during the perinatal development of rat ccrcbcllum. Neuroscience 13:1217-1241.

Wassef M, Zanetta JP, Brehier A, Sotelo C (1985) Transient biochemical compartmentalization of Purkinje cells during early cerebellar development. Dev Biol 111:129-137.

Wassef M, Sotelo C, Thomasset M, Granholm AC, Leclerc N, Rafrafi J, Hawkes R (1990) Expression of compartmentation antigen zebrin I in cerebellar transplants. J Comp Neurol 294:223-234.

Wassef M, Chédotal A, Cholley B, Thomasset M, Heizmann CW, Sotelo C (1992a) Development of the olivocerebellar projection in the rat. I. Transient biochemical compartmentation of the inferior olive. J Comp Neurol 323:519-536.

Wassef M, Cholley B, Heizmann CW, Sotelo C (1992b) Development of the olivocerebellar projection in the rat. II. Matching of the developmental compartmentations of the cerebellum and inferior olive through the projection map. J Comp Neurol 323:537-550.

Wolfer DP, Henehan-Beatty A, Stoeckli ET, Sonderegger P, Lipp H-P (1994) Distribution of TAG-1/Axonin-1 in fibre tracts and migratory streams of the developing mouse nervous system. J Comp Neurol 345:1-32

Yoshihara Y, Kawasaki M, Tani A, Tamada A, Nagata S, Kagamiyama H, Mori K (1994) BIG-1: a new TAG-1/F3-related member of the immunoglobulin superfamily with neurite outgrowth-romoting activity. Neuron 13:415-426. 